\title{
Creative Light-Emitting Imaging on Textiles Integrated with Laser-Ablated Polymer Optical Fibres
}

\author{
Frankie Ng*, Xiaoming Tao and Xiaoyong Mo \\ Institute of Textiles and Clothing, The Hong Kong Polytechnic University, China
}

*Corresponding author: Frankie Ng, Institute of Textiles and Clothing, The Hong Kong Polytechnic University, Hung Hom, Kowloon, Hong Kong, China submission: 㘹June 22, 2018; Published: 眥July 02, 2018

\begin{abstract}
This paper reports the proposition and validation of the concept of innovative optical displays on textiles that used the RGB colour mode as well as surface-treated light-emitting fabrics integrated with the created polymer optical fibre (POF) materials. The POFs used were step-index optical fibres with a PMMA fibre core and a fluorinated PMMA derivative cladding. This type of structure exhibits suitable light transmission, thus overcoming the issue of leakage. The fabric structure was plain weave and the pattern of POF as the weft yarns was made of a set of three RGB colours used as a pixel unit. The colour was controlled by the RGB combination, and the light-emitting intensity was controlled by the number of notches produced through laser ablation on the POF. Weaving automatic loom machine and CO2laser machine were used to conduct experimentation and for subsequent creations. The successful creation of optical display on surface-treated light-emitting fabrics integrated with POF materials, a new design trend combined with POF materials on the basis of the RGB colour mode through laser micromachining technology resulted in innovative textiles. This in turn leads to the ultimate re-definition of art (fashion), humanities, and technology, which re-shape our culture and lifestyle and further enhance research in this area.
\end{abstract}

Keywords:Creative image display; Creative textiles; Polymer optical fibre; Laser micromachining

\section{Background}

The past 40 years have seen the development of a new type of optical fibre, called POF [1]. This fibre is traditionally composed of a homogeneous core in polymethyl-methacrylate (PMMA) with a higher refractive index and cladded by fluorinated polymers with a lower refractive index. Until now, POFs have been developed, inter alia, for data communication and for networks in buildings, automobiles, railways, and aviation. These fibres have gradually started attracting attention in the textile industry because of their light weight, flat surface, and flexibility (Figure 1) [2]. These characteristics have made them easily connectable to light sources, such as light-emitting diodes (LEDs), thus rendering them suitable for large-area illumination [3] and adjustable in three-dimensional (3D) displays on wearable devices [4].

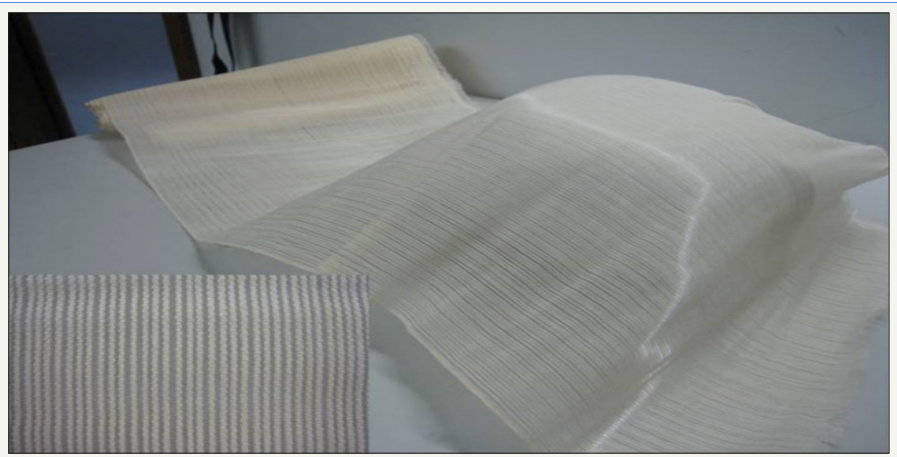

Figure 1: Photograph of woven fabrics produced from cotton yarns and POF of diameter 250 $\mu \mathrm{m}$ [13].

This paper reports the study which aimed to explore, expand, and invent new weaving patterns using the RGB colour mode integrated into a fabric sheet. Every set of RGB colors (as weft yarns) serves as one pixel unit with cotton yarns as the wrap yarn.
A broad array of colours can be reproduced and controlled by the RGB combination, and light-emitting intensity can be adjusted according to the number of notches created by $\mathrm{CO}_{2}$ laser ablation on the POF surface. The new designs emerge toward full colour 
optical displays on fabrics that cannot be otherwise manufactured using existing methods. The success of identifying, expanding, and inventing new weaving techniques with the new colour mode is of both original artistic merit and commercial value and will be a key design direction in this area. Consequently, the exciting creations from this project have attracted substantial interest in optical display fabrics for the public at large. Through this technology, fabrics integrated with POF using the RGB color mode will be significant in enhancing the design and technological values of textile and clothing merchandises in the increasingly competitive international fashion market.

\section{POF to textile}

Optical fiber connected with a light source was first developed more than 150 years ago by using glass [5]. With the development of plastic fibers in the 1960s, the concept of lighting fabrics by using POF in textile structures was published as a patent by DuPont in 1967 [6].

Today, processing of optical fibersin differenttextile technologies has led to various applications in displays, communication devices [3], and sensors, such as in medical, healthcare, architecture, public premises, stage, fashion design, and security and military devices.
With connection to an external light source, POFs integrated in textiles allow light transmission not only to selected locations but also on the textile surface. For example, Kaschke [7] invented a light-emitting apparatus, called flexible flat panel displays 20 years ago. With the integration of light in textiles, many companies have caught up with the trend of combining modern design and functionality and have patented relevant up-to-date products. Remarkably, fibers or fiber-based systems have spurred numerous patents within the last century [8].

POF sensors are also well known [9]. Recently, scientists developed POFs as sensors for such applications as structural health monitoring [10] and strain and temperature detection [11].

\section{Display technology with integration of POF in fabrics}

Perpendicularly oriented fibers of warp and weft can present images and information on flexible wearable substrates that exhibit information or designs on, for example, cars, portable electronic devices, and buildings, with the accelerated development of optoelectrical methods, especially LEDs (Figures 2a \& 2b). Knocar [3] was the first one to produce flexible woven displays in cooperation with France telecom.

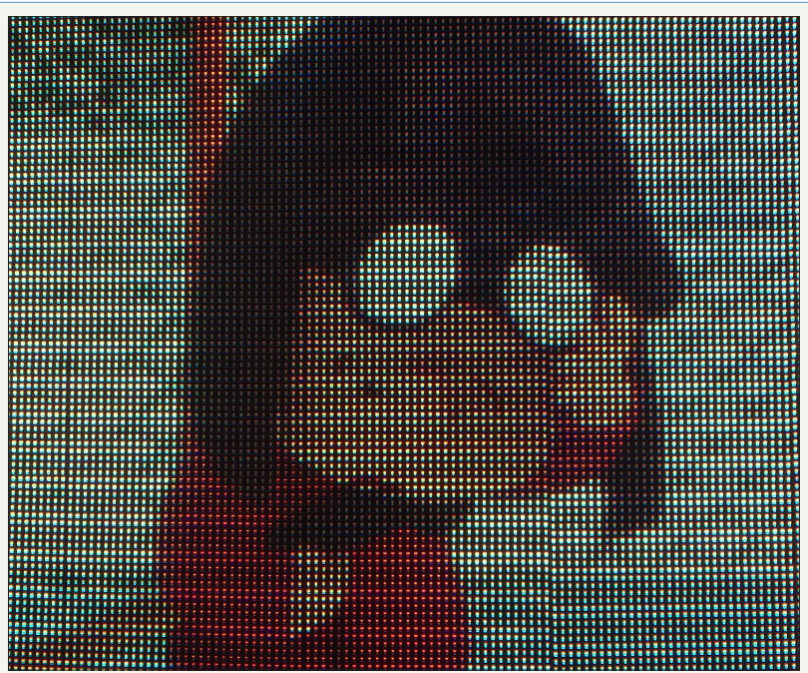

Figure 2a : LED display based on RGB matrix clusters.

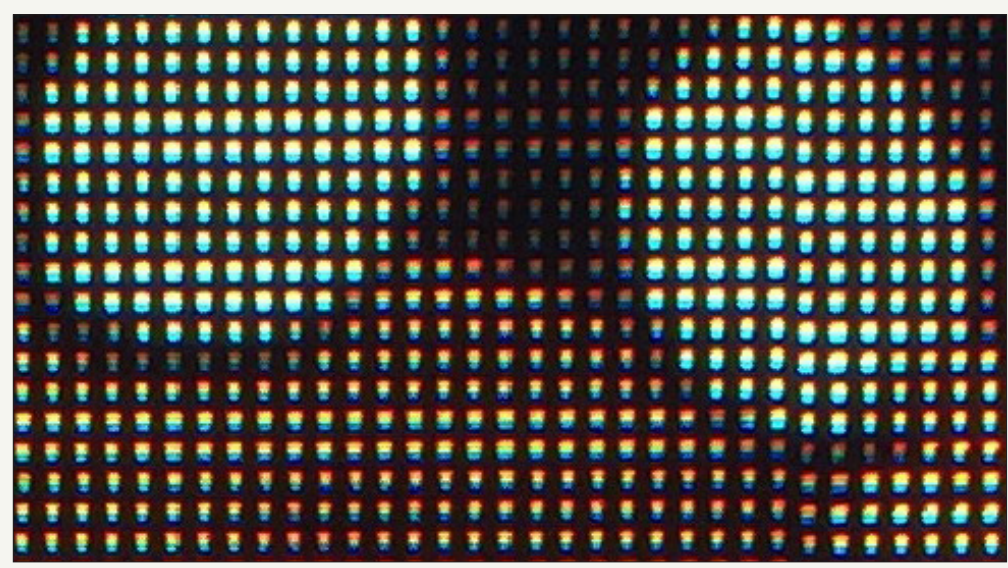

Figure $\mathbf{2 b}$ : Close-up of a portion of the LED display based on RGB matrix clusters. 
Optical fibers and LEDs are not only well established in the fields of optoelectronics and telecommunications, but also being applied in the textile industry to striking effect. Scientists have now learnt how to weave optical fibers and integrate them with textiles as well as manufacture flexible LED arrays and light-emitting fabrics [12]. The result is a new breed of visually striking photonic clothing that not only looks good but also has serious applications as 'luminous fabrics devices' (medical dressings for light therapy) [13] and garments with enhanced visibility and dynamic signage for pedestrians and cyclists [2].

\section{Principle of light emission}

To acquire controlled pattern or colour, scientists have manufactured flexible LED displays and fabrics mainly using side- emitting POFs. The LED screen for fabric displays is composed of numerous surface units or pixels, each of which can be illuminated by light emitted from PMMA optical fibers with discrete index variation from one side of the fabric. The pixels are directly formed on optical fibers while transversely forming a spout of light on the fabric. This process generates micro-perforations, which reach the fiber core. The rest of the optical fiber, without any specific processing, transmits light on the surface while being invisible [3]. By using laser technology, certain features can be created in the core or at the core-cladding interface of the fiber; thus, the POF can emit light sideways, which offers possibilities for making exaggerated fashion statements and creating various design patterns [14] (Figures 3a \& 3b).

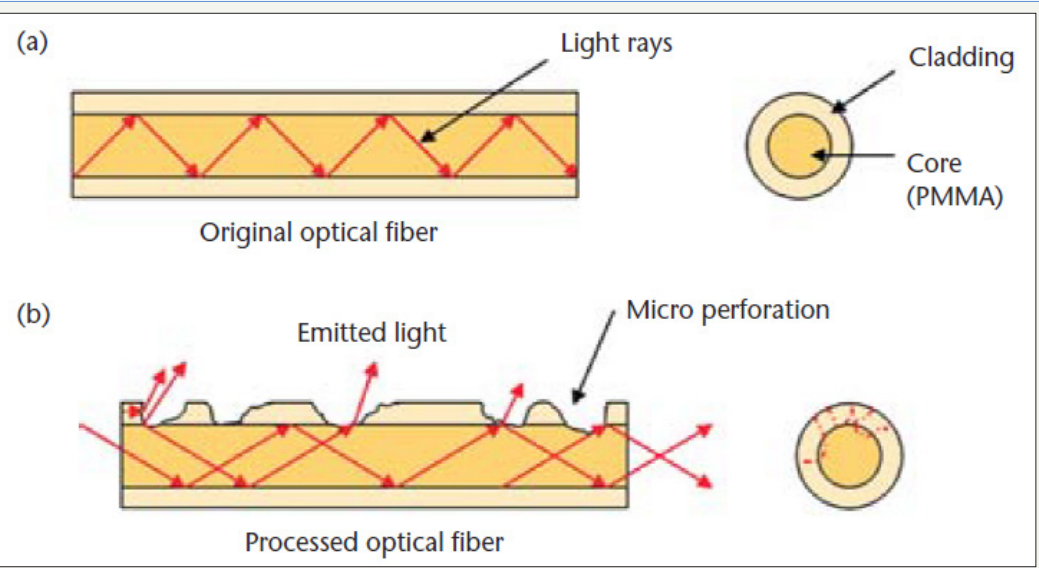

Figure 3a : Laser ablated POF enabling light emission sideway.

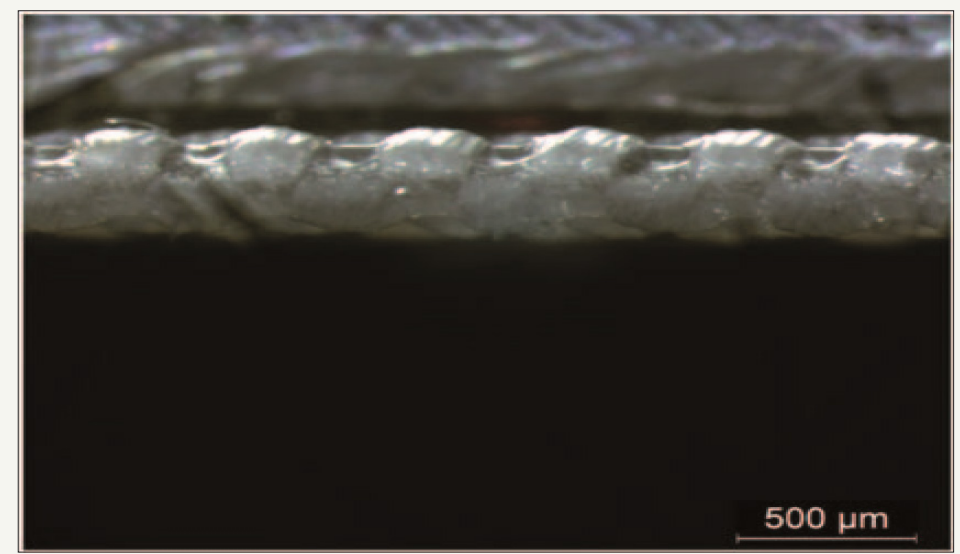

Figure 3b : Laser ablated POF enabling light emission sideway.

\section{Laser technology}

Advances in laser technology have progressed so rapidly during the past decades that successful treatments have been developed and used for many aspects [15], such as laser micromachining technology on textile materials. Surface modification by chemical finishing methods is not environmentally friendly and can cause safety and pollution problems [16]. Consequently, laser technology applied as a physical treatment method is becoming widely adopted; it can be used in various applications to improve or even eliminate several problems of the traditional processes [17].
Designed patterns can be quickly and easily formed on POF surfaces by using laser [18]. A laser micromachining system with a computer graphic facility is a simple and controllable method for treating a large-sized POF [19]. $\mathrm{CO}_{2}$ infrared lasers are often used to ablate the underlying photo-thermal material. When the focused laser beam meets the material surface, the temperature of the irradiated spot increases so rapidly that the material melts, decomposes, and vaporizes, thus leaving a void in the work piece [20]. 
Laser ablation of polymers has been extensively investigated. For example, Srinivasan [21] discussed the relevance of photochemical and photo-thermal mechanisms in UV laser ablation. In addition, Cheng et al. [22] developed a flexible pipeline, improving the surface smoothness and easily introducing various functional groups on PMMA fabrics through laser micro machining.

PMMA micro fluidic systems are produced by a commercial $\mathrm{CO}_{2}$ laser system $[23,24]$. Surface properties, effects of laser power, and the processing speed of polymer materials irradiated by $\mathrm{CO}_{2}$ laser, including polyethylene terephthalate [25], polyethylene [26], polyester, and polyamide have also been investigated, which provides useful information on laser photo-thermal ablation on POFs exhibiting predetermined lights.

Despite the studies on laser micromachining technology and fabricated POF displays, surface-treated POFs with various patterns using the RGB colour mode integrated into a fabric sheet have not been investigated. Hence, several design possibilities can be explored for such POFs, and it is clear that the future development of optical display on fabrics in the fashion market will be a key research and design direction.

This study proposed to invent and adopt a completely new approach and method to realize a full-coloured light-emitting image creation on fabrics integrated with polymer optical fibre using laser micromachining technology which has not been conceived of and/or made possible before. The results of which were of high innovative application value and tremendous commercialization viability in terms of material and human resources. Successful outcomes of this project not only benefit application of the results in the fashion and textile industry, but also increased the competitiveness of nations which rely on the important role of their fashion and textile industry. The outcomes also further enhanced future research in this area.

\section{Methodology}

The initial phase of the proposed project was exploratory. A comprehensive review of the literature on POF fabrics and infrared laser micromachining technology was conducted to identify and expand the existing knowledge in these areas toward the creation of optical fabrics in the fashion market. Based on this accumulated information, the scope of the project was made increasingly specific and focused as the project progresses. Technologies and materials that are of high relevance and potential applicability to optical fabrics were selected and explored under controlled experimentation toward optimal visual and practical effects. Weaving automatic loom machine and $\mathrm{CO}_{2}$ laser machine were used to conduct experimentation and for subsequent creations. Further experiments were conducted with the V2000 versatile laser system.

\section{Fabrics integrated with POF on the basis of RGB colour mode}

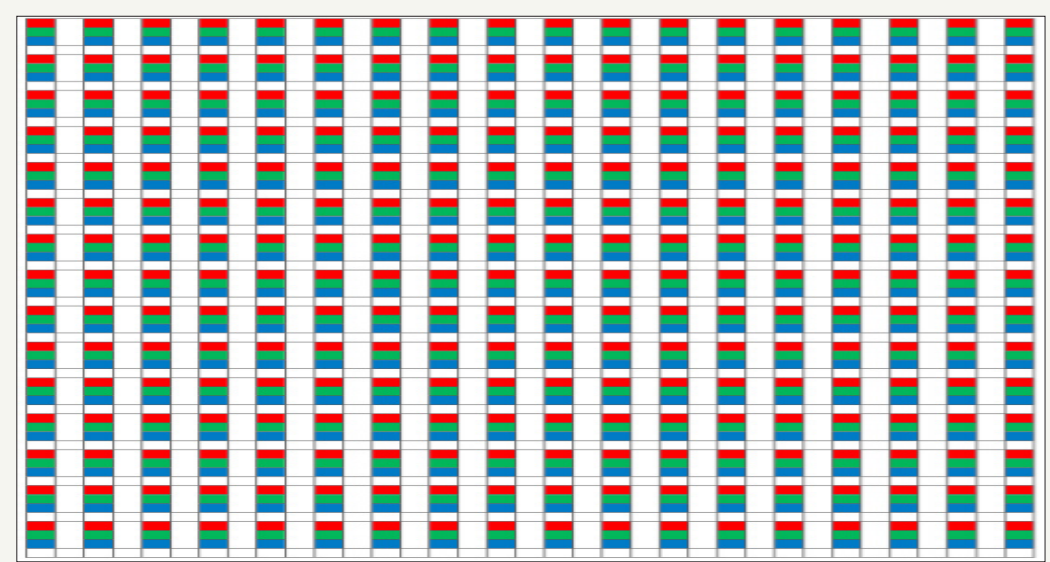

Figure 4a : Pattern of POF as the weft yarns and cotton as the warps proposed.

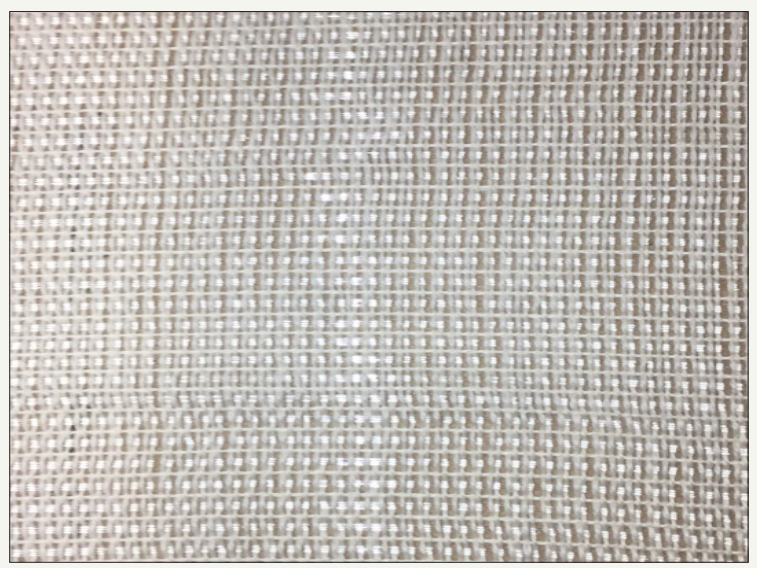

Figure $\mathbf{4 b}$ : The fabric with POF as the weft yarns and cotton as the warps produced. 
The POFs used (ESKATM, CK-10, supplied by Mitsubishi Rayon Co., Ltd., Japan) were step-index optical fibers with a PMMA fiber core and a fluorinated PMMA derivative cladding. This type of structure exhibits suitable light transmission, thus overcoming the issue of leakage. The fiber diameter is $250 \mu \mathrm{m}$ and the numerical aperture is 0.5 . The fibers were woven as the weft yarn with cotton yarns (32s/2, Central Textile, Hong Kong) as the wrap yarn by an automatic loom (the CCI Automatic Sample Loom SL7900). The fabric structure was plain weave (Figure $4 \mathrm{a} \& 4 \mathrm{~b}$ ).

\section{Direct-write laser machining treatment on light- emitting fabrics integrated with POF}

A commercial $\mathrm{CO}_{2}$ laser system (Jeanologia Flexi-e V2) was used for laser micromachining. The pulsed $\mathrm{CO}_{2}$ laser has a wavelength of $10.6 \mathrm{~mm}$, and the duty cycle of the input power pulses is $50 \%$. In this study, the beam width (spot size) is $0.2 \mathrm{~mm}$ and the beam divergence of the laser is less than $2.0 \mathrm{~m}$ rad. The output power density of the laser is $1.012 \mathrm{~W} / \mathrm{cm}^{2}$, which was measured using a laser power/energy meter (842-PE, Newport, USA). The cladding layer was removed by $\mathrm{CO}_{2}$ laser ablation, and the influencing factors, namely scanning speed and laser power density, were investigated.

\section{Experiments on weaving structure}

The initial weaving structures with each set of three fibers as a pixel unit were (a) 3/3 rib, (b) 3/2 matt weave, (c) 3/3 matt weave, (d) 6/6(2) matt weave, (e) 9/9(3) matt weave, (f) 3/1 plain+rib, (g) $(3+1) 2+1 / 3$ matt weave, (h) $3 / 1(2=2)$ matt weave, (i) $3 / 1(3+1)$ matt weave, and (j) $3 / 1(3+2)$ matt weave (Figure $5 a-5 j)$. The final selected weaving structures for optical laser ablation effect were (a) $3 / 3 \mathrm{rib}$, (c) 3x3 matt weave, (f) 3/1 plain + rib, and (g) (3/1)2+1/3 matt weave.

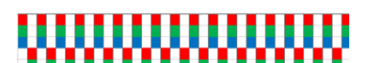 iminn $\min \mathrm{nin}$ $\operatorname{minimin}$ $\operatorname{minm}$ }

(a)

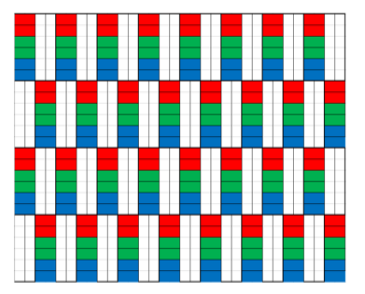

(d)

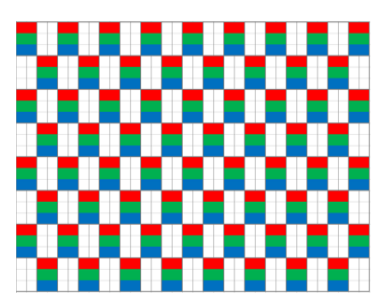

(b)

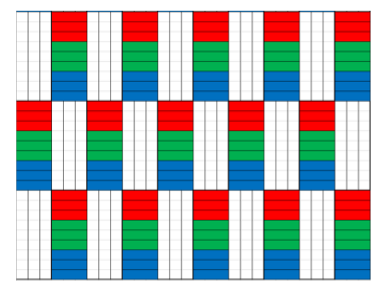

(e)

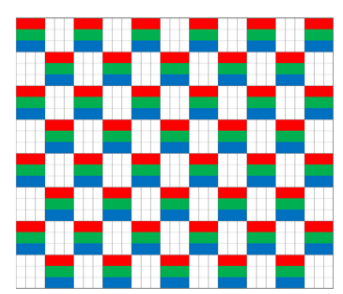

(c)

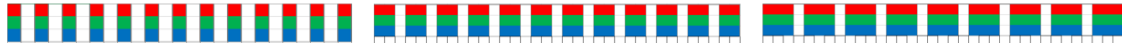

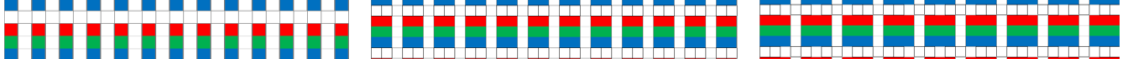 IIIIIIII

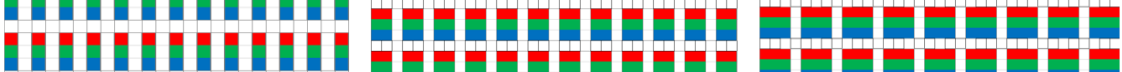

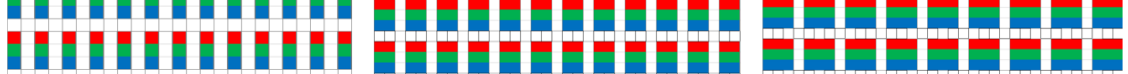

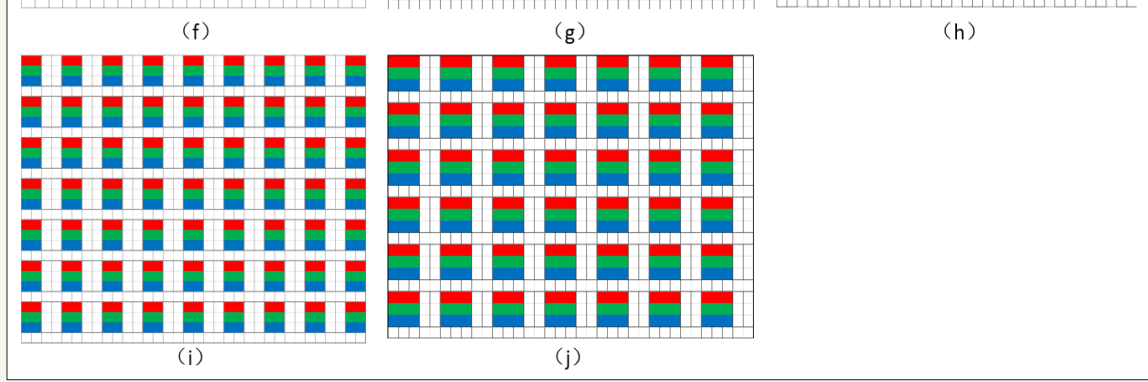

Figure 5(a-j) : Initial weaving structures with each set of three fibers as a pixel unit: (a) $3 / 3$ rib, (b) $3 / 2$ matt weave, (c) $3 / 3$ matt weave, (d) 6/6(2) matt weave, (e) 9/9(3) matt weave, (f) 3/1 plain+rib, (g) $(3+1) 2+1 / 3$ matt weave, (h) $3 / 1(2=2)$ matt weave, (i) $3 / 1(3+1)$ matt weave, (j) 3/1(3+2) matt weave.

Groups of photonic fibers are bundled together and then connected with LEDs with predetermined sequences. By this way, the POF fabric can present a unique appearance with multiple and mixed colours (Figure 6). 


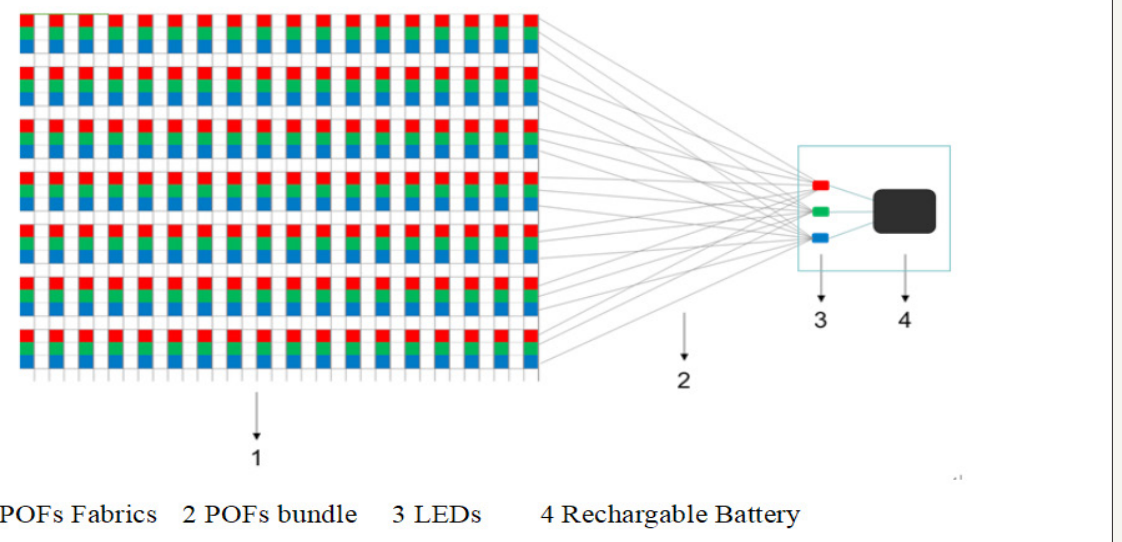

Figure 6 : Groups of photonic fibers bundled and connected with LEDs with predetermined sequences.

\section{Experiments on laser micromachining POF}

In this study, laser micromachining was deployed to remove part of the cladding of POF to allow light to emit on pre-designated spots along the surface of optical fibres. The fabric was placed on a platform, a laser beam was shoot on the surface of the fabric with POFs. The laser power was determined by two parameters: resolution (in dpi) and pixel time (in $\mu$ s).

When POFs having treated with $20 \mathrm{dpi}$ and $130 \mu$ s for 4 to 9 repeats, the engraving on POFs was acceptable. When the repeats were below 3 times, the engraving appeared insufficient. When the repeats were more than 10 times, the POF cores would break apart. When the POF was scanned by laser for 9 repeats, the ablation was not sufficient when treated with the parameters of $20 \mathrm{dpi}$ and $120 \mu \mathrm{s}$. It was found that 3 repeats were not sufficient when the POFs were treated with $20 \mathrm{dpi}$ and $140 \mu \mathrm{s}$. Compared with $20 \mathrm{dpi}$ and $130 \mu \mathrm{s}$, the engraved depth was similar when the POFs were treated with 5 to 7 repeats. However, when the repeats were up to 9 repeats, the POFs broke. When POFs were treated with 30dpi and 1 repeat, the laser ablated surface become rough and overlapping of ablated spots occurred. POFs have been severely burned and broken off when they were engraved with $30 \mathrm{dpi}$ and $120 \mu \mathrm{s}, 130 \mu$ s and $140 \mu \mathrm{s}$ in 1 repeat. It can be concluded that laser micromachining with $30 \mathrm{dpi}$ is not suitable for ablating the POFs used in this research. It was found that it was sufficient for POFs to treat with $2 \mathrm{dpi}$ and $140 \mu$ s for 5 to 9 repeats. When POF was laser ablated with $20 \mathrm{dpi}$ and $130 \mu \mathrm{s}$, the engraving was insufficient even if the POF was scanned by laser for 9 repeats. When it reached 10 repeats, emit light began to emit.

\section{Results}

Based on the above finding with the images captured from the optical microscope, it can be concluded that a $250 \mu \mathrm{m}$ POF fabric to be engraved with a resolution of $20 \mathrm{dpi}$, a pixel time of $130 \mu$ s and 4 to 9 engraving repeats, and a $500 \mu \mathrm{m}$ POF fabric to be engraved with a resolution of $20 \mathrm{dpi}, 140 \mu$ s pixel time and 5 to 9 repeats can achieve a satisfactory removal of POF cladding with no broken and overlapping for a satisfactory illuminating effect. The results enabled a fabric integrated with POFs to emit a colour spectrum from primary to tertiary shades of colours (Figure 7).

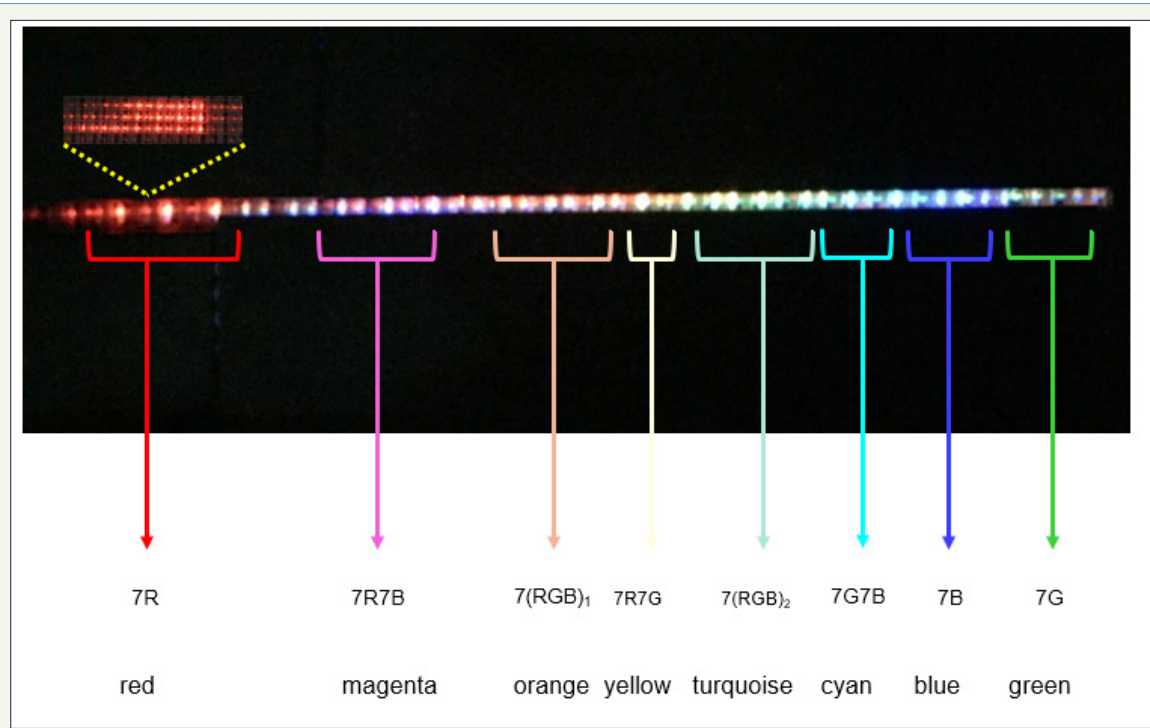

Figure 7 : Light emitting POFs fabrics in rainbow gradation. 


\section{Acknowledgment}

This research was funded by the Innovation and Technology Commission under the Innovation and Technology Fund of project and account numbers: ITS/149/16 - ZBP3.

\section{References}

1. Zubia J, Arrue J (2001) Plastic optical fibers: An introduction to their technological processes and applications. Optical Fiber Technology 7(2): 101-140.

2. Selm B, Gu“ rel EA, Rothmaier M (2010) Polymeric optical fiber fabrics for illumination and sensorial applications in textiles. Journal of Intelligent Material Systems and Structures 21(11): 1061-1071.

3. Koncar V (2005) Optical fiber fabric displays. Optics and Photonics News 16(4): 40-44.

4. Shen J, Tao X, Ying D (2013b) Light-emitting fabrics integrated with structured polymer optical fibres treated with an infrared $\mathrm{CO}_{2}$ laser. Textile Research Journal 83(7): 730-739.

5. Brochier C, Lysenko AA (2008) Optical fiber fabrics. Fibre Chemistry 40: 303-307.

6. Derick BN, Synder JS (1967) Luminous textile products. Du Pont, USP Office, USA.

7. Kaschke KD (1996) Optical fiber light emitting apparatus. Motorola, Inc, USP Office, USA.

8. Dhawan A, Ghosh TK, Seyam A (2005) Fiber-based electrical and optical devices and systems. Textile Progress 36: 1-84.

9. Bartlett RJ, Philip-Chandy R, Eldridge P, Merchant DF, Morgan R, et al. (2000) Plastic optical fibre sensors and devices. Transactions of the Institute of Measurement and Control 22: 431-457.

10. Kuang KSC, Quek ST, Koh CG, Cantwell WJ, Scully PJ (2009) Plastic optical fibre sensors for structural health monitoring: A review of recent progress. Journal of Sensors 2009: 1-13.

11. Peters K (2010) Polymer optical fiber sensors-a review. Smart Mater Struct 20(1): 1-17.

12. Tao XM, Cheng XY, Yu JM (2008) Photonic fabric display with controlled pattern, colour, luminescence intensity, scattering intensity and light self-amplification. Patent 7466896, USA.
13. Shen J, Chui CH, Tao XM (2013a) Luminous fabric devices for wearable low-level light therapy. Biomed Opt Express 4(12): 2925-2937.

14. Graham-Rowe D (2007) Photonic fabrics take shape. Nature Photonics 1: 6-7.

15. Tanzi EL, Lupton JR, Alster TS (2003) Lasers in dermatology: Four decades of progress. J Am Acad Dermatol 49(1): 1-34.

16. Esterves F, Alonso H (2007a) Effect of $\mathrm{CO}_{2}$ laser radiation on surface properties of synethics fibres. Research Journal of Textile and Apparel 11(3): 42.

17. Ortiz-Morales M, Poterasu M, Acosta-Ortiz SE, Compan I, HernandexAlvarado MR (2003) A comparison between characteristics of various laser-based denim fading processes. Optics and Lasers in Engineering 39(1): 15-34.

18. Georgiou S, Kautek W, Kruger J (2004) Polymers and light. Springer, Berlin, Germany.

19. Li B, Yu H, Sharon A (2004) Rapid three-dimensional manufacturing of micro fluidic structures using a scanning laser system. Appl Phys Lett 85: 2426-2428.

20. Kawagoe M, Nakanishi M, Qui J (1997) Growth and healing of a surface crack in poly (methyl methacrylate) under case II diffusion of methanol. Polymer 38: 5969-5975.

21. Srinivasan R (1993) Ablation of polymethyl methacrylate films by pulsed (ns) ultraviolet and infrared $(9.17 \mathrm{~mm})$ lasers: a comparative study by ultrafast imaging. J Appl Phys 73: 2743-2750.

22. Cheng JY, Wei CW, Hsu KH (2004) Direct-write laser micromachining and universal surface modification of PMMA for device development. Sens Actuators B 99(1): 186-196.

23. Klank H, Kutter JP, Geschke O (2002) $\mathrm{CO}_{2}$-laser microma- chining and back-end processing for rapid production of PMMA-based micro fluidic systems. Lab Chip 2(4): 242-246.

24. Snakenborg D, Klank H, Kutter JP (2004) Microstructure fabrication with a $\mathrm{CO}_{2}$ laser system. J Micromech Microeng 14(2): 82-89.

25. Dadsetana M, Mirzadehb H, Shari N (1999) Effect of $\mathrm{CO}_{2}$ laser radiation on the surface properties of polyethylene terephthalate. Radiat Phys Chem 56(5-6): 597-604.

26. Dadbin S (2002) Surface modification of LDPE film by $\mathrm{CO}_{2}$ pulsed laser irradiation. Eur Polym J 38(12): 2489-2495.
Creative Commons Attribution 4.0 International License

For possible submissions Click Here

\section{Submit Article}

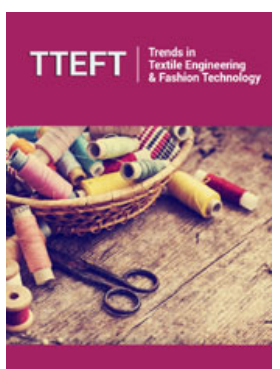

Trends in Textile Engineering \& Fashion Technology

\section{Benefits of Publishing with us}

- High-level peer review and editorial services

- Freely accessible online immediately upon publication

- Authors retain the copyright to their work

- Licensing it under a Creative Commons license

- Visibility through different online platforms 